Article

\title{
Social Support Networks and the Mental Health of Runaway and Homeless Youth
}

\author{
Eric R. Wright ${ }^{1, *}$ (D), Brandon K. Attell ${ }^{2}$ (i) and Erin Ruel ${ }^{1}$ \\ 1 Department of Sociology, Georgia State University, P.O. Box 5020, Atlanta, GA 30302, USA; eruel@gsu.edu \\ 2 Georgia Health Policy Center, Georgia State University, P.O. Box 3992, Atlanta, GA 30302, USA; \\ battell1@gsu.edu \\ * Correspondence: ewright28@gsu.edu; Tel.: +1-404-413-6527
}

Received: 8 July 2017; Accepted: 26 September 2017; Published: 29 September 2017

\begin{abstract}
In response to growing concerns about the rising number of runaway and homeless youth (RHY) in the U.S., researchers have sought to improve the scientific understanding of health and mental health needs, as well as the social resources available to these youths. In this paper, we examine the relationship between personal support network resources and the mental health status of a sample of RHY $(\mathrm{N}=693)$ surveyed in metro-Atlanta, Georgia. The results suggest that having more supportive network ties reduces the risk of youth experiencing significant symptoms of a severe mental illness. We also find that older youth and youth who have been homeless for six months or longer have fewer personal support network resources. We conclude with a discussion of the implications of our findings for future research and services for this exceptionally vulnerable population.
\end{abstract}

Keywords: runaway and homeless youth; homelessness; personal networks; social support; mental health; severe mental illness

\section{Introduction}

Over the past two decades, policymakers and social service providers have become increasingly alarmed about the growing number of runaway and homeless youth (RHY) living independently on the streets, in shelters, or in other precarious situations across the U.S. (Fernandes-Alcantara 2013; U.S. Department of Health and Human Services, Family and Youth Services Bureau 2013). In 2016, the U.S. Department of Housing and Urban Development (HUD) reported based on its annual Point-in-Time (PIT) estimate of the homeless that, across the U.S., "[t]here were 35,686 unaccompanied homeless youth, roughly seven percent of the total homeless population and 10 percent of people experiencing homelessness as individuals" (Henry et al. 2016, p. 44). Because of the difficulties in defining "unattached" youth and because they often are invisible in traditional systems for serving homeless people, most researchers and homeless advocates believe that the true population of "unaccompanied" RHY is much larger, somewhere between 1 and 1.7 million youth (Fernandes-Alcantara 2013; National Coalition for the Homeless 2017; U.S. Department of Health and Human Services, Family and Youth Services Bureau 2013).

There are many reasons youth runaway or become homeless. Many are kicked out of their homes or leave because of family conflict or dysfunction (Bannon et al. 2012; Castellanos 2016). Others find themselves homeless because of poor discharge planning or limited support services for youth leaving the child welfare or juvenile justice systems (Castellanos 2016; Dworsky et al. 2012). Familial residential instability and economic hardship have also been identified as significant forces in the lives of many RHY (National Coalition for the Homeless n.d.). While the reasons vary, research indicates that RHY experience significant health and mental health challenges (for a recent review, see (Edidin et al. 2012)). At the same time, a few studies also found that these young people can be 
incredibly resourceful and resilient and that social network support is often a critical resource for managing their difficult life circumstances (Irwin et al. 2008; Kidd and Shahar 2008; Rew et al. 2001; Snyder et al. 2016; Unger et al. 1998).

In this paper, we explore the relationship between social support networks and mental health in a sample of RHY surveyed as part of a community-wide needs assessment in Atlanta, Georgia (Wright et al. 2016). To the best of our knowledge, this is the first comprehensive needs assessment survey of RHY in the U.S. South. We begin by examining the size and composition of these youth's perceived support networks to determine how access to supportive personal network ties may vary by age and other demographic and homeless characteristics. Next, we examine whether access to perceived supportive personal network ties is associated with having a serious mental illness.

\subsection{The Health and Mental Health of RHY}

Given the myriad of difficult stressors RHY face on the streets, it is not surprising that researchers and service providers have documented a wide-range of physical and mental health problems (Edidin et al. 2012). Perhaps most importantly, RHY report exceptionally high levels of "overlapping" or interrelated traumas, including physical, sexual, and emotional abuse, both in their past and while they are homeless (Davies and Allen 2017). Other studies indicate that these youth engage in frequent sexual risk behavior and often have high rates of STI/HIV infection (Auerswald et al. 2006; Gwadz et al. 2010; Tyler 2013). RHY frequently turn to or are exposed to alcohol and other drugs, which can result in significant patterns of abuse and sometimes even clinical dependence (Bannon et al. 2012; Bender et al. 2014; Kipke et al. 1997; Tyler 2013). Regarding mental health, researchers have documented high levels of depressive symptoms and psychological distress (Edidin et al. 2012; Kamieniecki 2001; Toolis and Hammack 2015), as well as suicidality and suicide attempts (Fulginiti et al. 2016; Moskowitz et al. 2013). Consistent with the well documented high-prevalence of severe mental illness among homeless youth and adults (Henry et al. 2016; National Health Care for the Homeless Council 2015), severe mental illness has also been found to be a significant concern among RHY, particularly post-traumatic stress, anxiety, and other major mood disorders (Davies and Allen 2017; Edidin et al. 2012; Nyamathi et al. 2005).

\subsection{The Support Networks of RHY}

Decades of prior theory and research has documented the central importance of social integration and social support for mental health generally and for coping with difficult life circumstances specifically (for comprehensive reviews, see (Hartwell and Benson 2007; Thoits 2011)). In this paper, we focus on the personal support networks of youth, or the set of people that youth perceive to be available to them as potential sources of social support. This sub-set of individuals' broader social networks have been found to be particularly influential when it comes to understanding people's mental health status and/or their use of mental health services (Perry and Pescosolido 2015; Wellman 2007). Personal support networks, however, have been measured operationally in a variety of ways (Scott 2017; Wellman 2007). The parent project, on which this study is based, operationalized RHY's personal support networks as the number of connections youth perceived to be available across four relationship domains (i.e., family, friends, adults, and professionals) to "talk to" and/or "depend on" regarding important matters. The "important matters" approach to enumerating the number and describing the composition of personal support networks has been used successfully across a wide-range of general social surveys, as well as more specialized studies of mental health (see for example (Marsden 1987; Perry et al. 2017; Perry and Pescosolido 2015)). This ego-centered approach to collecting network data typically captures the core supports in a person's life who actively provide various forms of emotional, instrumental, and/or informational support, which are especially important for maintaining mental health and managing stress (Perry et al. 2017). Unfortunately, the practical constraints of administering an omnibus survey to RHY in the field prohibited including detailed questions about the nature or quality of their relationship beyond the number of ties within each relational category. 
Interest in the social networks of RHY first emerged in the mid-to-late 1990s as researchers recognized that this population was at an elevated risk of STI/HIV infection. While the initial focus was on homeless youth's sexual networks and contacts, a handful of research teams have now begun to explore the nature, role, and dynamics of personal social network ties in the lives of RHY (De la Haye et al. 2012; Tyler and Melander 2011). More importantly, this small, but growing body of work suggests that the process of becoming homeless, as well as life on the streets, pose numerous challenges for youth and adults to maintain or develop networks of supportive relationships (Dank et al. 2015; Ennett et al. 1999; Falci et al. 2011; McCarthy and Hagan 1992; Tyler 2008). Indeed, many of the causes of youth homelessness reflect a breakdown in family support systems and/or the failure of formal care systems to provide adequate support to facilitate a youth's transition to adulthood (Edidin et al. 2012; Fernandes-Alcantara 2013). At the same time, becoming homeless often involves a disruption in a youth's social and physical location that challenges both their sense of self, as well as the reorganization of their personal networks, which for most youth are heavily place-based (Falci et al. 2011; Toolis and Hammack 2015; Tyler and Melander 2011). Indeed, in the one longitudinal study to date, researchers found that homeless youth's networks tend to deteriorate and get smaller the longer that they are homeless (Falci et al. 2011). Some RHY, however, do manage to maintain connections to old family and friends and may even develop new network ties "on the streets," and these social ties are often critical supports for youth struggling with homelessness (Ennett et al. 1999; Falci et al. 2011; Rice et al. 2005, 2007, 2008; Tyler and Melander 2011; Unger et al. 1998). In short, when it comes to the structure of RHY's personal networks, they appear to be smaller, more dynamic, and possibly more varied in composition than the personal support networks of similarly aged youth in the general population.

The impact of these personal network ties on the health and well-being of RHY is more complex. For many years, the prevailing "risk amplification" view was that the failure to form strong family bonds drove RHY to form street networks of youth that caused and reinforced a range of maladaptive behaviors, ranging from minor delinquency to criminal behavior to frequent use of drugs and alcohol and high risk sexual behavior (Ennett et al. 1999; Rice et al. 2007). Indeed, the bulk of the existing literature provides empirical evidence that RHY's personal networks-especially when they include older peers or other youth who are engaged in or express support for risky behavior-increase the likelihood that RHY will engage in more frequent minor criminal activity and sexual and substance use risk behavior (Bannon et al. 2012; Barman-Adhikari et al. 2016; Ennett et al. 1999; Jacobson et al. 2008; Rice et al. 2007; Tucker et al. 2012; Tyler 2008, 2013).

At the same time, having access to "prosocial" supports-most notably other youth who are in school or employed or supportive family ties-has also been found to have a protective effect among RHY and be associated with lower rates of problem behavior (Rice et al. 2007). A few scholars have documented that having access to social support is associated with fewer negative mental health symptoms among homeless youth and can reduce the frequency of suicidality and other maladaptive behaviors (Castro et al. 2014; Fulginiti et al. 2016; Irwin et al. 2008; Moskowitz et al. 2013; Unger et al. 1998). Social support from personal networks can also offer critical instrumental coping assistance in finding employment and being successful in finding housing (Barman-Adhikari and Rice 2014; Holtschneider 2016). The literature also hints that ties to supportive professionals may be particularly influential in increasing the likelihood that RHY access services when available (Tyler et al. 2012; Wright and Connoley 2002). The fact that the support networks of RHY can serve both positive and negative functions is not surprising, given the extensive literature on the role of social networks in health (see (Smith and Christakis 2008) for a review).

The impact of support networks on RHY, however, has proven to be difficult to capture and fully understand. As described in the literature reviewed above, RHY's network connections are dynamic, varied, and deeply embedded in their immediate social surroundings. At the same time, the RHY population is remarkably heterogeneous with regard to age, race/ethnicity, sexuality, gender identity, length of time homeless, and many other clinical, behavioral, and social characteristics (Toro et al. 2011). However, our understanding of how these factors organize the social lives and 
networks of RHY is extremely limited. Consequently, at the most basic level, we seek to contribute to this small, but growing literature by probing the relationship between age, race/ethnicity, gender identity, sexual identity, and time homeless and RHY's access to personal support network resources. Because access to social support is central for positive mental health, we go further and investigate the association between personal support network resources and having serious mental health problems among RHY. While we know that adolescence and young adulthood involve significant psychosocial developmental challenges that are dynamically intertwined with changes in the structure of young people's social networks (Cotterell 2013), Falci et al. (2011) have documented that access to personal support networks deteriorates the longer that youth are homeless. However, during our field work for a large community needs assessment of homeless youth aged 14 to 25 in Atlanta, Georgia, we also observed that younger RHY were more likely to cope with life on the streets by banding together in small groups or "crews" (Wright et al. 2016). Our field experience led us to wonder whether age or the length of time a youth was homeless was more important in understanding the dynamics of network change. In this paper, we use our cross-sectional survey data to begin to explore the independent effects of age and time homeless in shaping both the personal support network resources and the mental health status of homeless youth.

\section{Methods}

\subsection{Data and Sample}

The data for this study come from the 2015 Atlanta Youth Count and Needs Assessment (Wright et al. 2016). Developed through a community-university partnership, the study centered around an anonymous field survey of RHY. The survey was conducted in the summer of 2015 on the streets and in various shelters and service locations across metro-Atlanta. Teams of outreach service providers worked with student researchers to identify, recruit, and ultimately survey youth who indicated that they were between the ages of 14 and 25, did not have a permanent stable residence of their own for at least one day in the past month, and who were living independently without consistent parental or family support. The anonymous survey was completed on paper by trained student interviewers who were supervised by the study directors and a team of field supervisors. The survey took, on average, approximately $20 \mathrm{~min}$ to administer. The survey instrument was designed to collect basic information about each youth's experiences being homeless and their contact with various social service systems. In addition, the youth were asked about the frequency that they engaged in several health risk and protective behaviors, as well as their overall health and mental health status.

The survey data were collected following capture-recapture methods with two, two-week survey sweeps of areas identified by service providers, policymakers, and advocates as key locations where homeless and runaway youth congregate (see (Wright et al. 2016) for a more complete discussion of the survey methodology). Youth who completed the survey received a $\$ 10$ gift card, as well as a list of resources where they could access additional services. The outreach workers also were available to provide immediate assistance to the participating youth, if needed and/or requested. Because the survey was anonymous and youth could complete the survey multiple times over the field period, we included several questions that could be concatenated to form a distinctive identifier to distinguish unique respondents in the final data set. All study procedures were reviewed, approved, and monitored by the Institutional Review Board at Georgia State University.

The final dataset included a number of youth that we believe completed the survey more than once, as well as a handful of surveys that were discarded because of poor data quality. In this paper, we focus on our final sample of 693 de-duplicated, unique homeless youth. The majority of the sample (70.9\%) was between 20 and 25 years old, with an average age of 21.5 (SD = 2.6; range: 15-25). With regard to race/ethnicity, the majority of our sample designated their racial-ethnic identity as Black or African American (71\%) or Multiracial or Biracial (16.1\%). We also asked a series of questions that invited respondents to describe their current gender and sexual identity. Approximately $60.5 \%$ of the 
youth surveyed self-identified as cisgender men, while $32.9 \%$ described themselves as being cisgender women, indicating that their gender assigned at birth was consistent with their current gender identity. Forty-five (6.5\%) of the youth described themselves as "transgender," "gender non-conforming," or some other self-label indicating that they did not conform to a traditional gender category. Nearly three quarters $(73.2 \%)$ labeled themselves as "Straight", with the remainder categorizing themselves as "Gay or Lesbian" (13.8\%), "Bisexual" (10.9\%), or "Something Else" (2.2\%). For about half (49.6\%) of our respondents, it was the first time that they had been homeless and $34.8 \%$ indicated having been homeless for two months or less. A significant number of youth (39.7\%), however, indicated that they had been homeless for six months or longer. The most common reasons for being homeless cited by the youth in our study were financial problems (48.1\%), job problems (32.2\%), family violence or problems $(28.2 \%)$, being kicked out (24.2\%), and/or housing problems $(23.7 \%)$.

\subsection{Measures}

\subsubsection{Mental Health Status}

Mental health status was assessed utilizing the Kessler Psychological Distress Scale, "K6" (Kessler et al. 2002). The K6 was originally developed as a unidimensional measure of non-specific psychological distress for the U.S. National Health Interview Survey (NHIS) and has since been implemented in the U.S. National Household Survey on Drug Abuse (NHSDA), the Australian National Survey of Mental Health and Well-Being, and many community-based studies of mental health. Repeated psychometric testing of the K6 in nationally representative and community-based samples indicates that the scale has strong reliability and validity (Kessler et al. 2002, 2003, 2010; Mewton et al. 2016). Importantly, the K6 demonstrates strong discrimination properties that correlate scale scores with clinically significant indicators of probable severe mental illness (Kessler et al. 2010).

During data collection, respondents were asked to report how often they felt nervous, hopeless, restless or fidgety, so depressed that nothing could cheer them up, that everything was an effort, or worthless during the past 30 days. Responses were coded at the ordinal level as none of the time (0), a little of the time (1), some of the time (2), most of the time (3), and all of the time (4). Despite the widespread use and popularity of the $\mathrm{K} 6$, divergent methods have been adopted to score the scale for use in research. One approach has been to sum the unweighted raw scores of responses to all six items and categorize participants into a dichotomous grouping of non-probable severe mental illness (scores of zero to 12) or probable severe mental illness (scores of 13 to 24) (Kessler et al. 2010). An alternative approach, set forth by the seminal psychometric testing of the scale as it was adopted for the NHIS, has been to utilize a weighted sum of all six items derived from a maximum-likelihood item response theory model (Kessler et al. 2002).

As a measure of robustness, in this study we utilized both the dichotomous grouping and weighted score approach. As such, a dichotomous indicator of probable severe mental illness was calculated as discussed above. Additionally, a weighted sum was calculated using polytomous item response theory modeling. Due to the ordinal nature of the six scale items, the weighed score was estimated using Samejima's graded response model (Samejima 1969). The graded response model utilizes a maximum-likelihood estimation procedure to predict responses to ordinal scale items and is parameterized as:

$$
\operatorname{Pr}\left(Y_{i j} \geq k \mid a_{i}, b_{i}, \theta_{j}\right)=\frac{\exp \left\{a_{i}\left(\theta_{j}-b_{i k}\right)\right\}}{1+\exp \left\{a_{i}\left(\theta_{j}-b_{i k}\right)\right\}}, \theta_{j} \sim N(0,1)
$$

where the probability of responding in a particular item category $k$ is conditioned on an item's discrimination $\left(a_{i}\right)$, item's difficulty $\left(b_{i}\right)$, and the latent trait of the individual $\left(\theta_{j}\right)$, assumed to be normally distributed with a mean of zero and standard deviation of one. Once the graded response model was estimated, the weighted $\mathrm{K} 6$ score was calculated using the steps outlined by Flowers et al. (1999): 


$$
\text { IRT Scaled Response }=\sum_{i=1}^{n} \sum_{j=1}^{m} \operatorname{Pr}_{i j}\left(\theta_{j}\right) X_{i j}
$$

where $\operatorname{Pr}_{i j}$ is the conditional probability of responding to each item-level category given an individual's latent trait and $X_{i j}$ represents the weight given to each item-level category response.

\subsubsection{Social Network Support}

The number of social support ties from family members, friends, adults, and professionals was measured by asking respondents the following four questions: (1) "Do you have family members you can talk to about important matters or turn to for help when you have a problem?"; (2) "Do you have friends your age you can talk to about important matters or turn to for help when you have a problem?"; (3) "Do you have adult friends you can talk to about important matters or turn to for help when you have a problem?"; and, (4) "Do you have professionals you can talk to about important matters or turn to for help when you have a problem?" Respondents were presented with three possible ordinal responses: none (0); one to three (1); and, four or more (2). If respondents requested clarification, interviewers were trained to define family members as "people who were related to the respondent by birth or marriage." Adults were operationalized as "individuals or friends who were older than 25 years of age." Professionals were defined as ties that they interacted with who were providing healthcare, social services (including homeless service providers), or other professional care or support.

\subsubsection{Demographic Variables}

Across all models, demographic variables for age, race, gender, sexuality, transgender, and time homeless were employed. Age was coded as a continuous variable, with responses ranging from 15 to 25 years of age, and then scaled by subtracting 15 from the age of each respondent. Because most individuals in the sample were black, race was coded as an indicator where one represents black respondents and zero represents non-black respondents. Non-black individuals included those who self-identified as white, Native American, Asian, Hispanic, Pacific Islander, biracial, multiracial, or some other race. Gender was coded using a series of three indicators to identify cisgender men, cisgender men, and transgender or gender variant youth (for most analyses cisgender men served as the referent category). Sexuality was coded as a separate indicator dummy variable where one represents an individual who self-identified as lesbian or gay and zero represents individuals who were not lesbian or gay.

Because the duration of homelessness may be an important determinant of mental health status and social support network composition, it was employed as a control variable. During survey administration, respondents were asked: how long have you been homeless this time (that is, continuously homeless since your last permanent housing)? Respondents were provided with several response categories, which for the purposes of this analysis, were represented as a series of indicators. The referent category was less than one month to two months homeless, with subsequent indicators for two to six months homeless, six months to one year homeless, and more than one year homeless.

\subsection{Analytic Procedures}

We began our analysis by examining the demographic predictors of social support network composition. This was carried out in two ways. First, binary logistic regression was used to estimate separate models for each of the four types of social support outlined above (family members, friends, adults, and professionals). For the purposes of the logistic regression models, the original three-category responses for family members, friends, adults, and professionals were collapsed into a binary response such that zero represents all individuals who responded "none" and one represents all individuals who responded either "one to three" or "four or more." Second, recognizing that social support may not always function in such a discrete manner, we then calculated a continuous social 
support measure by summing the values of the responses to all four of the original support variables, with higher values representing greater levels of social support. The continuous social support measure was then used as a dependent variable in an ordinary least squares (OLS) regression with the same set of demographic predictor variables as the logistic regression.

Next, we examined the relationship between social support and mental health status, controlling for the demographic variables outlined above. Because the K6 was scored as both a dichotomous indicator and IRT-scaled response, two separate models were run: a binary logistic regression for the dichotomous outcome and an OLS regression for the IRT-scaled K6. In both models, we utilized a forward stepwise approach to first examine the relationship between the demographic variables and mental health status. The second portion of the stepwise models then nested in social support.

The analysis was restricted to individuals with non-missing data on all study variables $(n=652)$. All analytic procedures were performed in $R$ version 3.3.3 ( $R$ Core Team 2017). The binary logistic regression models were estimated using the glm function and the OLS regression models were estimated using the $\mathrm{lm}$ function in base $R$ ( $R$ Core Team 2017). The K6 weighted score derived from Samejima's graded response model was estimated using the ltm package (Rizopoulos 2006). All graphics were created using the ggplot2 package (Wickham 2009).

\section{Results}

Descriptive statistics for all study variables are provided in Table 1. Regarding mental health status, $28 \%$ of the individuals in this sample met the threshold for a clinically significant indicator of probable severe mental illness. The mean of the IRT-scored K6 scale was 9.02, with a standard deviation of 4.95. Sixty percent of youth had social support from adults and family members, while $65 \%$ had support from friends and $40 \%$ from professionals. The mean of the continuous social support measure was 2.99 , with a standard deviation of 2.05. The mean of the scaled age variable was 6.50, with a standard deviation of 2.56. Most of the individuals in the sample were black (71\%) and one-third of the sample were cisgender women (33\%). Twenty-five percent of youth were homeless between two months and six months, $15 \%$ were homeless between six months to one year, and $24 \%$ were homeless for more than one year. Relatively few individuals in the sample were lesbian or gay (14\%) or transgender $(6 \%)$.

Table 1. Descriptive Statistics.

\begin{tabular}{ccc}
\hline & Mean or Proportion & Standard Deviation \\
\hline Mental Health Status & & - \\
Probable Severe Mental Illness & 0.28 & - \\
Non-probable Severe Mental Illness & 0.72 & 4.95 \\
IRT-Scored Kessler 6 & 9.02 & - \\
\hline Social Support & & - \\
\hline Adults & 0.60 & - \\
Family & 0.60 & - \\
Friends & 0.65 & 2.05 \\
Professionals & 0.40 & 2.56 \\
Continuous Social Support Measure & 2.99 & - \\
\hline Demographic Variables & & - \\
Age, scaled & 6.50 & - \\
Black & 0.71 & - \\
Cisgender Woman & 0.33 & - \\
Homeless 2 Months To 6 Months & 0.25 & - \\
Homeless 6 Months To 1 Year & 0.15 & - \\
Homeless More than 1 Year & 0.24 & 0.14 \\
Lesbian or Gay & 0.06 & \\
Transgender & &
\end{tabular}

Odds ratios and 95\% confidence intervals for the logistic regressions predicting the presence of the four different types of social support are presented in Table 2. To aid with interpreting these results, the coefficients are also plotted visually in Figure 1. Compared to cisgender men, cisgender women 
were less likely to have social support from adults (O.R. $=0.70, p=0.04)$. Compared to non-black individuals, black individuals were more likely to have support from family members (O.R. = 1.48, $p=0.02$ ). Individuals who self-identified as lesbian or gay were more likely to have support from professionals (O.R. $=1.69, p=0.02$ ) compared to individuals who did not identify as lesbian or gay. For three of the social support mechanisms, there was a significant negative effect between the duration of homelessness and support status. Compared to those who reported being homeless for less than one month to two months, those who were homeless for six months to one year (O.R. $=0.55, p=0.02)$ and more than one year (O.R. $=0.52, p=0.003$ ) were less likely to have support from family members. Similarly, those who were homeless for six months to one year were also less likely to have support from friends (O.R. $=0.55, p=0.02)$ and professionals (O.R. $=0.58, p=0.04)$.

Table 2. Logistic Regression of the Presence of Different Types of Support Network Ties.

\begin{tabular}{|c|c|c|c|c|}
\hline & Adults & Family & Friends & Professionals \\
\hline Age & $\begin{array}{c}1.00 \\
(0.94-1.07)\end{array}$ & $\begin{array}{c}0.99 \\
(0.93-1.05)\end{array}$ & $\begin{array}{c}0.93 * \\
(0.87-0.99)\end{array}$ & $\begin{array}{c}0.93 * \\
(0.87-0.99)\end{array}$ \\
\hline Black & $\begin{array}{c}0.91 \\
(0.64-1.29)\end{array}$ & $\begin{array}{c}1.48^{*} \\
(1.04-2.09)\end{array}$ & $\begin{array}{c}1.13 \\
(0.79-1.63)\end{array}$ & $\begin{array}{c}0.89 \\
(0.63-1.27)\end{array}$ \\
\hline Cisgender Woman & $\begin{array}{c}0.70 * \\
(0.50-0.99)\end{array}$ & $\begin{array}{c}1.10 \\
(0.77-1.56)\end{array}$ & $\begin{array}{c}0.87 \\
(0.61-1.25)\end{array}$ & $\begin{array}{c}1.02 \\
(0.72-1.45)\end{array}$ \\
\hline Homeless 2 Months To 6 Months & $\begin{array}{c}1.37 \\
(0.90-2.09)\end{array}$ & $\begin{array}{c}0.82 \\
(0.54-1.26)\end{array}$ & $\begin{array}{c}1.27 \\
(0.81-1.98)\end{array}$ & $\begin{array}{c}1.04 \\
(0.69-1.57)\end{array}$ \\
\hline Homeless 6 Months To 1 Year & $\begin{array}{c}0.97 \\
(0.60-1.57)\end{array}$ & $\begin{array}{c}0.55^{*} \\
(0.34-0.90)\end{array}$ & $\begin{array}{c}0.55 * \\
(0.34-0.90)\end{array}$ & $\begin{array}{c}0.58^{*} \\
(0.35-0.97)\end{array}$ \\
\hline Homeless More than 1 Year & $\begin{array}{c}0.82 \\
(0.54-1.24)\end{array}$ & $\begin{array}{c}0.52 * * \\
(0.34-0.80)\end{array}$ & $\begin{array}{c}0.79 \\
(0.51-1.22)\end{array}$ & $\begin{array}{c}0.74 \\
(0.49-1.14)\end{array}$ \\
\hline Lesbian or Gay & $\begin{array}{c}1.45 \\
(0.88-2.39)\end{array}$ & $\begin{array}{c}0.69 \\
(0.43-1.12)\end{array}$ & $\begin{array}{c}1.14 \\
(0.68-1.89)\end{array}$ & $\begin{array}{c}1.69 * \\
(1.05-2.72)\end{array}$ \\
\hline Transgender & $\begin{array}{c}0.91 \\
(0.44-1.86)\end{array}$ & $\begin{array}{c}0.91 \\
(0.46-1.83)\end{array}$ & $\begin{array}{c}1.11 \\
(0.53-2.35)\end{array}$ & $\begin{array}{c}0.72 \\
(0.35-1.46)\end{array}$ \\
\hline Pseudo $\mathrm{R}^{2}$ & 0.01 & 0.02 & 0.02 & 0.02 \\
\hline
\end{tabular}

$\overline{\mathrm{N}=652 .{ }^{*} p \leq 0.05,{ }^{* *} p \leq 0.01,{ }^{* * *} p \leq 0.001 \text {. Odds ratios appear in cells; } 95 \% \text { confidence intervals appear }}$ in parentheses.

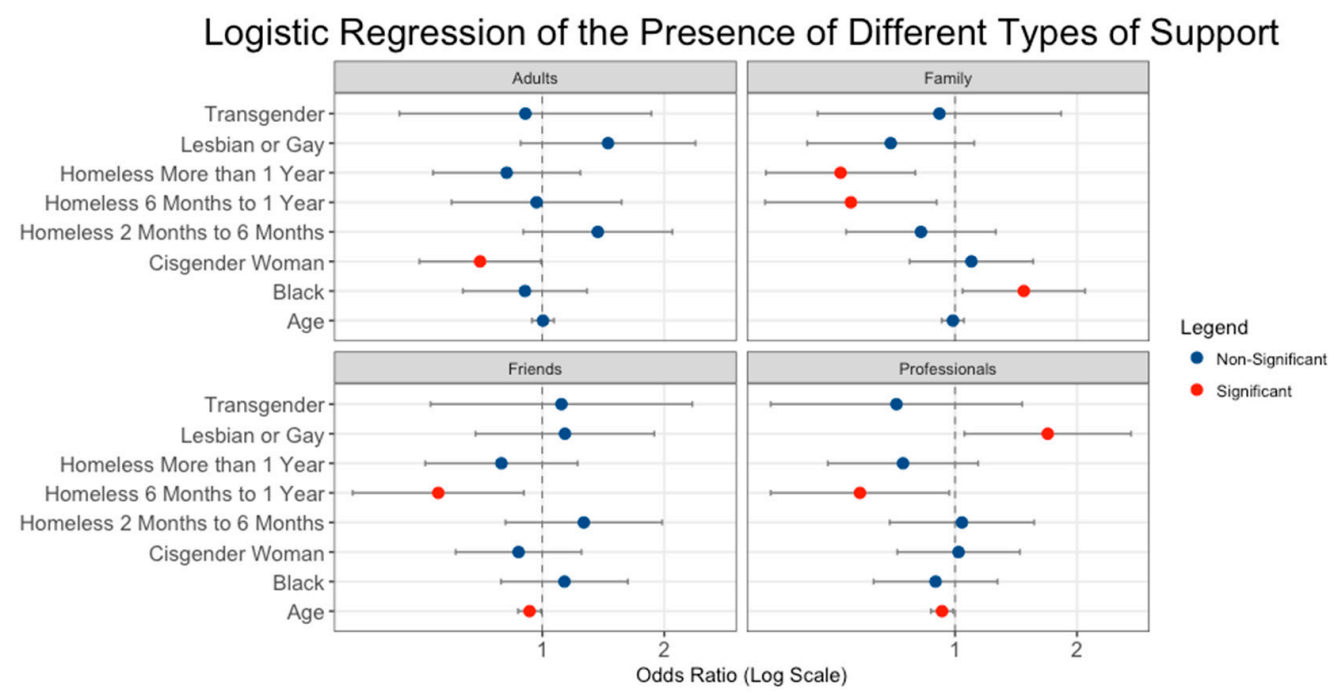

Figure 1. Odds ratios plot for logistic regression of the presence of different types of support. Dots represent the estimated odds ratio from the model, while lines represent the $95 \%$ confidence interval for each odds ratio. Blue dots represent non-significant effects while red dots represent statistically significant effects.

Across two measures of social support, there was a negative relationship between age and type of support. Specifically, older homeless youth are less likely to have support from friends (O.R. = 0.93, 
$p=0.03$ ) and professionals (O.R. $=0.93, p=0.02)$ compared to their younger peers. These significant age effects are plotted visually in Figure 2, which demonstrates the general downward relationship between age and the probability of having support from friends and professionals. The downward age effect for each of these relationships is quite notable. For example, there is a 21 percent difference in the probability of a 15-year-old and 25-year-old having support from professionals. Regarding support from friends, there is a $17 \%$ difference in the probability of support between 15 -year-olds and 25-year-olds.

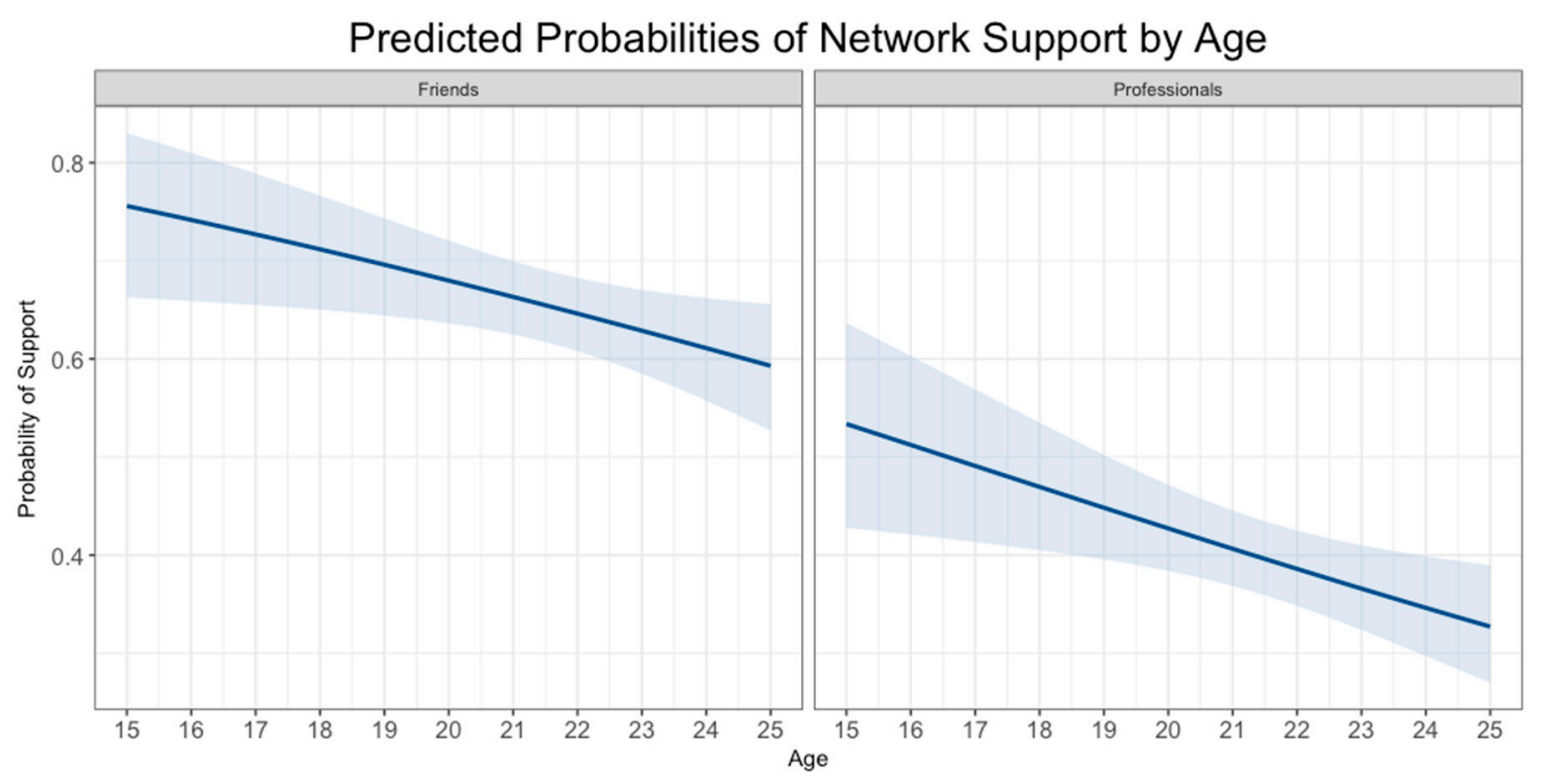

Figure 2. Predicted probabilities of network support by age.

The results of the OLS regression predicting the relationship between demographic variables and the continuous, summed support measure are displayed in Table 3. Similar to the support-separated logistic regression models, there were negative relationships between time homeless and the level of social support experienced by homeless youth. Specifically, compared to those who reported being homeless for less than one month to two months, youth who were homeless for six months to one year were expected to report 0.58 less social support mechanisms $(p=0.03)$. Additionally, compared to cisgender men, cisgender women were expected to report 0.46 less social support mechanisms $(p=0.009)$.

Table 3. OLS Regression of Continuous Support Measure.

\begin{tabular}{ccc}
\hline & Coefficient & 95\% Confidence Interval \\
\hline Intercept & $3.53^{* * *}$ & $(2.98-4.07)$ \\
Age & -0.05 & $(-0.11-0.01)$ \\
Black & 0.10 & $(-0.25-0.44)$ \\
Cisgender Woman & $-0.46^{* *}$ & $(-0.80--0.11)$ \\
Homeless 2 Months To 6 & 0.14 & $(-0.26-0.55)$ \\
Months & $-0.58^{*}$ & $(-1.06--0.10)$ \\
Homeless 6 Months To 1 Year & -0.40 & $(-0.81-0.02)$ \\
Homeless More than 1 Year & 0.23 & $(-0.24-0.70)$ \\
Lesbian or Gay & -0.22 & $(-0.91-0.47)$ \\
Transgender & 0.03 & \\
$\mathrm{R}^{2}$ & $\mathrm{~N}=652 .{ }^{*} p \leq 0.05,{ }^{* *} p \leq 0.01,{ }^{* * *} p \leq 0.001$. \\
\hline
\end{tabular}


The results of the binary logistic regression predicting probable severe mental illness are displayed in Table 4. In model 1, none of the demographic variables (age, race, gender, sexuality, transgender status, and time homeless) were statistically significant predictors of probable severe mental illness. However, in model 2, the continuous social support measure demonstrated a negative relationship with probable severe mental illness, such that for every one-unit difference in social support the likelihood of having a severe mental illness decreased by $15 \%(\mathrm{O} . \mathrm{R} .=0.85, p<0.001)$. This relationship is displayed visually in Figure 3. With the addition of the social support variable in model 2, the effects of most of the demographic predictors were slightly attenuated, suggesting that social support may be an important mediator of the relationship between the demographic variables and probable severe mental illness. The addition of the social support variable also accounted for about two percent more of the variance in probable severe mental illness than the demographic predictors alone.

Table 4. Logistic Regression of Probable Severe Mental Illness.

\begin{tabular}{|c|c|c|c|c|}
\hline & \multicolumn{2}{|r|}{ Model 1} & \multicolumn{2}{|r|}{ Model 2} \\
\hline & Odds Ratio & 95\% Confidence Interval & Odds Ratio & 95\% Confidence Interval \\
\hline Age & 0.99 & $(0.92-1.06)$ & 0.97 & $(0.91-1.05)$ \\
\hline Black & 0.86 & $(0.59-1.25)$ & 0.87 & $(0.59-1.27)$ \\
\hline Cisgender Woman & 1.29 & $(0.89-1.87)$ & 1.21 & $(0.83-1.77)$ \\
\hline Homeless 2 Months To 6 Months & 1.23 & $(0.78-1.95)$ & 1.27 & $(0.80-2.01)$ \\
\hline Homeless 6 Months To 1 Year & 1.80 & $(1.08-3.01)$ & 1.65 & $(0.98-2.78)$ \\
\hline Homeless More than 1 Year & 1.21 & $(0.75-1.93)$ & 1.13 & $(0.70-1.82)$ \\
\hline Lesbian or Gay & 0.86 & $(0.51-1.47)$ & 0.89 & $(0.52-1.52)$ \\
\hline Transgender & 1.99 & $(0.98-4.05)$ & 1.96 & $(0.95-4.02)$ \\
\hline Social Support Network & & & $0.85^{* * *}$ & $(0.77-0.93)$ \\
\hline Pseduo $\mathrm{R}^{2}$ & \multicolumn{2}{|r|}{0.01} & \multicolumn{2}{|r|}{0.03} \\
\hline
\end{tabular}

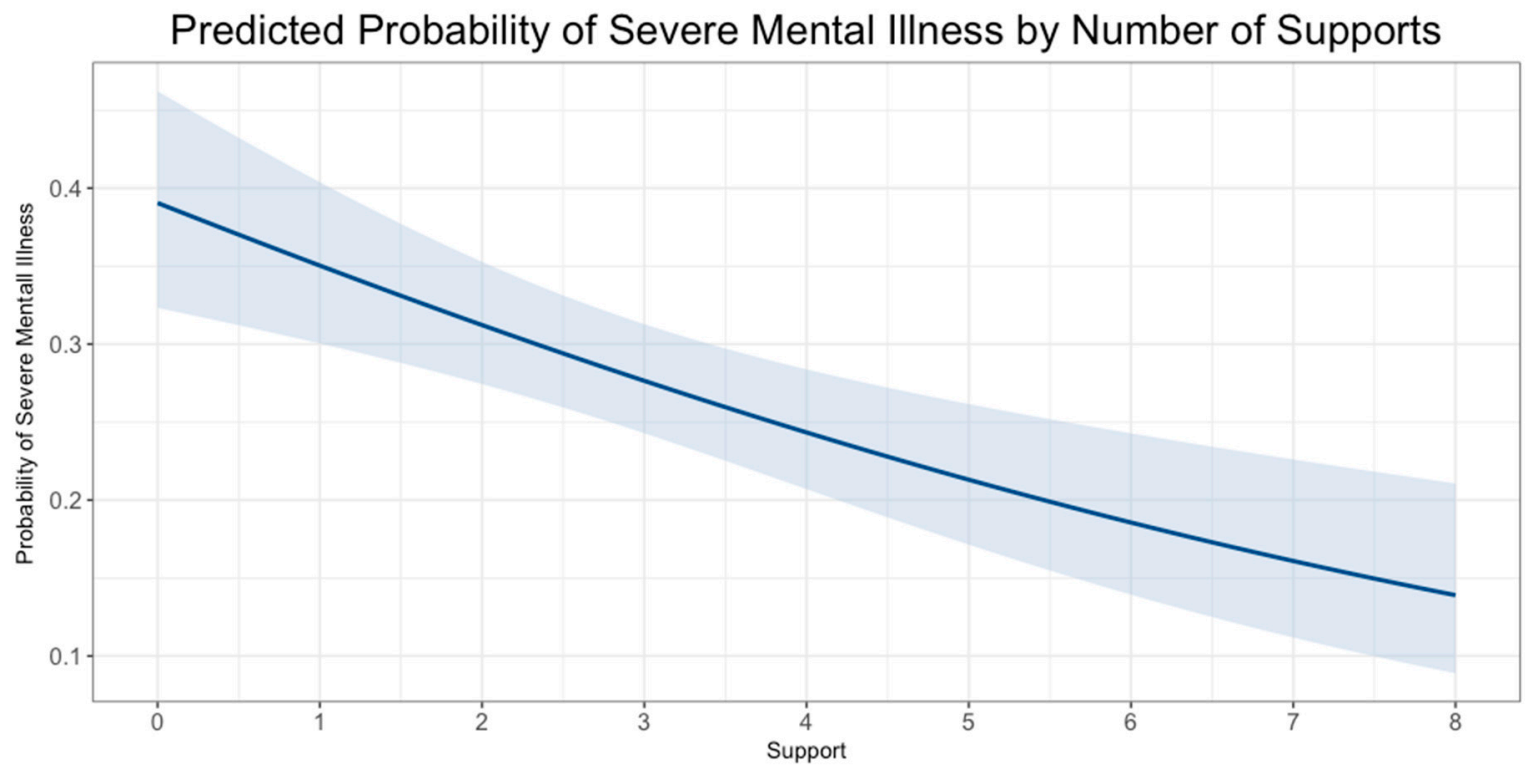

Figure 3. Predicted probability of severe mental illness by number of supports.

The results of the OLS regression predicting the relationship between demographic variables, social support, and the IRT-scaled K6 score are presented in Table 5. As presented in model 1, compared to cisgender men, cisgender women score 1.05 points higher on the $\mathrm{K} 6(\mathrm{~b}=1.05, p=0.01)$. Individuals who self-identified as transgender score 2.39 points higher in probable severe mental illness compared to their non-trans peers $(b=2.39, p=0.005)$. Compared to those who reported being homeless for less than one month to two months, those who were homeless for six months to one year score 1.31 points higher in probable severe mental illness $(b=1.31, p=0.03)$. As presented in model 2 , as the number 
of social supports increased, scores on the IRT-scaled K6 decreased ( $b=-0.33, p<0.001)$. With the addition of the social support variable in model 2, the significant effects for the cisgender woman, transgender, and homeless six months to one year indicators were all slightly attenuated. Similar to the logistic regression model predicting probable severe mental illness, this further suggests that social support may be an important mediator variable. Also similar to the logistic regression model, the addition of the social support variable explains about two percent more of the variance in the IRT scored $\mathrm{K} 6$ variable.

Table 5. OLS Regression of IRT-Scaled K6.

\begin{tabular}{|c|c|c|c|c|}
\hline & \multicolumn{2}{|r|}{ Model 1} & \multicolumn{2}{|r|}{ Model 2} \\
\hline & Coefficient & 95\% Confidence Interval & Coefficient & 95\% Confidence Interval \\
\hline Intercept & $7.92 * * *$ & $(6.60-9.23)$ & $9.08^{* * *}$ & $(7.62-10.53)$ \\
\hline Age & 0.05 & $(-0.09-0.20)$ & 0.04 & $(-0.11-0.19)$ \\
\hline Black & -0.32 & $(-1.16-0.52)$ & -0.29 & $(-1.12-0.54)$ \\
\hline Cisgender Woman & $1.05^{*}$ & $(0.25-1.88)$ & $0.90^{*}$ & $(0.08-1.73)$ \\
\hline Homeless 2 Months To 6 Months & 0.50 & $(-0.49-1.49)$ & 0.55 & $(-0.43-1.53)$ \\
\hline Homeless 6 Months To 1 Year & 1.31 * & $(0.14-2.47)$ & 1.12 & $(-0.04-2.27)$ \\
\hline Homeless More than 1 Year & 0.84 & $(-0.17-1.85)$ & 0.71 & $(-0.29-1.71)$ \\
\hline Lesbian or Gay & -0.37 & $(-1.51-0.77)$ & -0.29 & $(-1.43-0.84)$ \\
\hline Transgender & $2.39^{* *}$ & $(0.72-4.06)$ & $2.32 * *$ & $(0.66-3.97)$ \\
\hline Social Network Support & & & $-0.33^{* * *}$ & $(-0.51--0.14)$ \\
\hline $\mathrm{R}^{2}$ & & 0.03 & & 0.05 \\
\hline
\end{tabular}

\section{Discussion}

In at least two ways, our findings are consistent with prior studies of the personal support networks of RHY in other parts of the country. First, in our sample, the likelihood that youth exhibit symptoms indicative of severe mental illness declines when they report having more supportive personal network connections. While our network support questions operationally measured only core support ties (i.e., "important matters" ties), the overall pattern is quite similar to other studies that used slightly different approaches to measuring youth's personal networks (see Falci et al. 2011; Fulginiti et al. 2016; Moskowitz et al. 2013). In short, our findings offer additional support for the general hypothesis that support networks are vital resources for RHY as they manage the myriad of stressors associated with being homeless.

Second, we also observe a similar pattern first documented in the single longitudinal network study conducted to date by Falci et al. (2011): youth who have been homeless longer tend to have smaller support networks. In our case, the youth who indicated that they had been homeless continuously for six months to a year reported significantly fewer supports. While the coefficient for total support networks for youth who stated that they had been homeless for more than a year was also negative, it was not statistically significant. A close examination of the detailed data on the separate types of support indicate that the lack of significance for this subgroup may be attributable to the greater variability among the longer-term homeless youth in our sample. Black youth, for example, reported significantly more support from family and Lesbian/Gay youth reported significantly more support from professional ties. Ties to family were much less likely to be reported for those youth who indicated being homeless for more than a year.

Perhaps most significantly, our finding that the length of time homeless and age were independently associated with having smaller networks is potentially theoretically noteworthy. In summarizing the literature on RHY's networks, Falci and colleagues (Falci et al. 2011) note that the daily stressors of life on the streets; the weakened connections to home, neighborhoods, and schools; and greater social mobility result in conditions that make it difficult for RHY to maintain stable social networks. In their own empirical research, they add that youth with mental health problems, and in particular those with conduct disorders, may be especially vulnerable to increased social isolation the longer that they are homeless because their symptoms often disrupt social relationships. 
Our finding that age may have an independent impact on the structure of personal support networks may suggest that other developmental processes are involved in the propensity of homeless youth toward greater social isolation. In their qualitative in-depth narrative analysis of the lives of homeless youth, Toolis and Hammack (2015) propose that how homeless youth interpret their experiences and the degree that youth adopt or reject a master identity as a homeless person can impact how they cope with difficult circumstances. For these authors, social network ties can be influential in this interpretive process, but their study also highlights the central importance of individual agency. Tyler and Melander (2011) describe a similarly deliberative process and illustrate, using qualitative data, how gender, age, and role-relationships shape the decisions homeless youth make in managing their network ties. Our findings regarding age-group related differences, when considered in light of these qualitative studies, hint at the possibility that more complex developmental processes may be behind the social trajectories and health outcomes of RHY. In this regard, we concur with Falci et al.'s observation that: "Even as the social networks of adolescents re-configure, the size and composition of these networks continue to exert influence" and that further network research is needed Falci et al.'s (2011, p. 827). This general pattern is also intriguing given recent research on the dynamics of personal network change among homeless youth during the transition to adulthood (Blakeslee 2012; Pinkerton and Dolan 2007; Wenzel et al. 2012). Clearly, more research is needed to elucidate the nature and quality of support available to RHY, as well as the factors shaping the structure of their personal support networks; however, we go further and assert that we need a multi-level approach to fully understand the needs and experiences of RHY, one that links network dynamics with social and psychological characteristics, development processes, and objective structural living and socioeconomic conditions.

Somewhat surprisingly, our models of the relative risk of having a severe mental illness indicate that the only significant predictor is the extent the youth felt they had more supportive network ties. No demographic factors were associated with an increased likelihood of having a probable severe mental illness. In our analysis of the distribution symptoms of psychological distress, we did find that transgender and gender-variant youth stand out as having more significant levels of psychological distress. Unexpectedly, we found that cisgender identified women reported significantly lower levels of distress than cisgender men. The impact of having network support, though, was consistently negative regardless of how mental health problems were measured.

Like all studies, our research has important limitations. Because the original survey was designed to be a very brief, street-intercept survey, the data we had to analyze are extremely limited. Like most studies of RHY, we had very limited information about the pathways into homelessness or their struggles to find housing. As noted above, several researchers have demonstrated the promise of using qualitative data to begin to explore some of the nuances of these youth's dynamic lives, as well as their changing social networks (Toolis and Hammack 2015; Tyler and Melander 2011). We also relied on a very simple measure of the perceived number of supportive relationships rather than a formal network roster. Other studies have utilized modified network roster approaches (Tucker et al. 2012; Tyler 2008), as well as global measures of perceived support and/or the number of ties based on role relationships (Rice et al. 2007; Unger et al. 1998). Our method may be the most vulnerable to over-stating support resources. While this may not necessarily be a limitation, it does reflect a significant difference from the network generator questions used in other studies. Our data are also cross-sectional. To fully explore the dynamic relationship between age and the length of time a youth is homeless, we would need longitudinal data from youth who began their lives on the streets at different ages and who have been homeless for different lengths of time. Finally, we relied on the K6 because of its extensive utility in estimating the prevalence of severe mental illness in population samples. Unfortunately, it does not permit making specific diagnostic distinctions, which may be particularly important in understanding social network processes (see (Falci et al. 2011) for example) and making important clinical distinctions among subpopulations. Despite these limitations, our study adds to a growing body of literature that 
emphasizes the importance of considering the mental health needs and social networks for researching and serving RHY.

\section{Conclusions}

Runaway and homeless youth represent an exceptionally vulnerable, and largely invisible, population in communities across the U.S. Our study adds to a growing body of literature indicating that social network resources and processes are critically important for the mental health and well-being of RHY. Our research offers additional evidence that one of the costs of homelessness is increased social isolation and fewer support resources. While our methods varied somewhat from those used in prior studies, we observed similar network effects in this sample of Southern RHY, when most existing data from this population have been collected in southern California, a handful of Midwestern cities, or in the Northeastern urban centers of New York City and Washington DC.

While more research is needed to fully elucidate the causes and consequences of personal support networks, our study and related research point to the need to consider these factors more carefully in our efforts to help RHY. It is clear that RHY face real struggles in cultivating and maintaining the positive support networks that are critical for their mental and physical health and well-being. Policy makers and homeless service providers would be wise to consider ways in which they could adopt and incorporate more network-centered engagement and intervention strategies to improve the care available to youth who runaway or find themselves homeless.

Acknowledgments: First and foremost, we would like to thank the many youth who contributed their time to participate in this study. We also want to express our appreciation to the many students and community volunteers who served as field research assistants and survey administrators or helped in other ways to implement the parent study. Finally, we also want to recognize and express our gratitude to Calli Taylor, Morgan Justice Fuoco, Ana LaBoy, and Kara Tsukerman for their technical assistance in preparing the dataset for analysis.

Author Contributions: Eric Wright and Erin Ruel conceived, designed, and directed the parent study. Eric Wright conceptualized this paper, conducted preliminary analyses, and drafted the majority of the manuscript. Brandon Attell completed the final analyses, prepared the tables and figures included, and drafted the results section of the manuscript. All three authors participated in the final review and revision of the manuscript.

Conflicts of Interest: The authors declare no conflict of interest.

\section{References}

Auerswald, Colette L., Eiko Sugano, Jonathan M. Ellen, and Jeffrey D. Klausner. 2006. Street-based STD testing and treatment of homeless youth are feasible, acceptable and effective. Journal of Adolescent Health 38: 208-12. [CrossRef] [PubMed]

Bannon, William M., Jr., Nisha Beharie, Orly Olshtain-Mann, Mary McKay, Leah Goldstein, Mary Acri, Marni L. Lolacono-Merves, Laura J. Elwyn, Kosta Kalogerogiannis, Ervin Torres, and et al. 2012. Youth Substance Use in a Context of Family Homelessness. Children and Youth Services Review 34: 1-7. [CrossRef] [PubMed]

Barman-Adhikari, Anamika, and Eric Rice. 2014. Social networks as the context for understanding employment services utilization among homeless youth. Evaluation and Program Planning 45: 90-101. [CrossRef] [PubMed]

Barman-Adhikari, Anamika, Stephanie Begun, Eric Rice, Amanda Yoshioka-Maxwell, and Andrea Perez-Portillo. 2016. Sociometric network structure and its association with methamphetamine use norms among homeless youth. Social Science Research 58: 292-308. [CrossRef] [PubMed]

Bender, Kimberly, Sanna Thompson, Kristin Ferguson, and Lisa Langenderfer. 2014. Substance use predictors of victimization profiles among homeless youth: A latent class analysis. Journal of Adolescence 37: 155-64. [CrossRef] [PubMed]

Blakeslee, Jennifer. 2012. Expanding the scope of research with transition-age foster youth: Applications of the social network perspective. Child E Family Social Work 17: 326-36. [CrossRef]

Castellanos, H. Daniel. 2016. The Role of Institutional Placement, Family Conflict, and Homosexuality in Homelessness Pathways among Latino LGBT Youth in New York City. Journal of Homosexuality 63: 601-32. [CrossRef] [PubMed] 
Castro, Anne L., Erika L. Gustafson, Ashley E. Ford, Jennifer P. Edidin, Dale L. Smith, Scott J. Hunter, and Narijan S. Karnik. 2014. Psychiatric disorders, high-risk behaviors, and chronicity of episodes among predominantly African American homeless Chicago youth. Journal of Health Care for the Poor and Underserved 25: 1201-16. [CrossRef] [PubMed]

Cotterell, John. 2013. Social Networks in Youth and Adolescence. New York: Routledge.

Dank, Meredith, Jennifer Yahner, Kuniko Madden, Isela Bañuelos, Lilly Yu, Andrea Ritchie, Mitchyll Mora, and Brendan Conner. 2015. Surviving the Streets of New York. New York: Urban Institute, Available online: https:/ / www.urban.org/sites/default/files/publication/42186/2000119-Surviving-the-Streets-ofNew-York.pdf (accessed on 2 February 2017).

Davies, Benjamin R., and Nicholas B. Allen. 2017. Review: Trauma and homelessness in youth: Psychopathology and intervention. Clinical Psychology Review 54: 17-28. [CrossRef] [PubMed]

De la Haye, Kayla, Harold D. Green, David P. Kennedy, Annie Zhou, Daniella Golinelli, Suzanne L. Wenzel, and Joan S. Tucker. 2012. Who is supporting homeless youth? Predictors of support in personal networks. Journal of Research on Adolescence 22: 604-16. [CrossRef] [PubMed]

Dworsky, Amy, Keri-Nichole Dillman, M. Robin Dion, Brandon Coffee-Borden, and Miriam Rosenau. 2012. Housing for Youth Aging out of Foster Care: A Review of the Literature and Program Typology. Washington: Mathematica Policy Research, Inc.

Edidin, Jennifer P., Zoe Ganim, Scott J. Hunter, and Niranjan S. Karnik. 2012. The mental and physical health of homeless youth: A literature review. Child Psychiatry \& Human Development 43: 354-75. [CrossRef]

Ennett, Susan T., Susan L. Bailey, and E. Belle Federman. 1999. Social network characteristics associated with risky behaviors among runaway and homeless youth. Journal of Health and Social Behavior 40: 63-78. [CrossRef] [PubMed]

Falci, Christina D., Les B. Whitbeck, Dan R. Hoyt, and Trina Rose. 2011. Predictors of change in self-reported social networks among homeless young people. Journal of Research on Adolescence 21: 827-41. [CrossRef] [PubMed]

Fernandes-Alcantara, A. L. 2013. Runaway and Homeless Youth: Demographics and Programs (No. RL33785). Washington: Congressional Research Service.

Flowers, Claudia P., Takako Chris Oshima, and Nambury S. Raju. 1999. A description and demonstration of the polytomous-DFIT framework. Applied Psychological Measurement 23: 309-26. [CrossRef]

Fulginiti, Anthony, Eric Rice, Hsun-Ta Hsu, Harmony Rhoades, and Hailey Winetrobe. 2016. Risky integration: A social network analysis of network position, exposure, and suicidal ideation among homeless youth. Crisis: The Journal of Crisis Intervention and Suicide Prevention 37: 184-93. [CrossRef] [PubMed]

Gwadz, Marya, Charles M. Cleland, Robert Quiles, David Nish, John Welsh, Lucky S. Michaels, Jose L. Gonzales, Amanda S. Ritchie, and Noelle R. Leonard. 2010. CDC HIV testing guidelines and the rapid and convention testing practices of homeless youth. AIDS Education and Prevention 22: 312-27. [CrossRef] [PubMed]

Hartwell, Stephanie W., and Paul R. Benson. 2007. Social Integration: A Conceptual overview and two case studies. In Mental Health, Social Mirror. Boston: Springer, pp. 329-53.

Henry, Meghan, Rian Watt, Lily Rosenthal, Azim Shivji, Jill Khadduri, and Dennis P. Culhane. 2016. The 2016 Annual Homeless Assessment Report (AHAR) to Congress: Part 1, Point in Time Estimates. Washington: US Department of Housing and Urban Development, Available online: https: / /www.hudexchange.info/ resources / documents / 2016-AHAR-Part-1.pdf (accessed on 26 June 2017).

Holtschneider, Casey. 2016. A part of something: The importance of transitional living programs within a Housing First framework for youth experiencing homelessness. Children and Youth Services Review 65: 204-15. [CrossRef]

Irwin, Jay, Mark LaGory, Ferris Ritchey, and Kevin Fitzpatrick. 2008. Social assets and mental distress among the homeless: Exploring the roles of social support and other forms of social capital on depression. Social Science and Medicine 67: 1935-43. [CrossRef] [PubMed]

Jacobson, Isabel G., Margaret A. K. Ryan, Tomoko I. Hooper, Tyler C. Smith, Paul J. Amoroso, Edward J. Boyko, Gary D. Gackstetter, Timothy S. Wells, and Nicole S. Bell. 2008. Alcohol use and alcohol-related problems before and after military combat deployment. JAMA Journal of the American Medical Association 300: 663-75. [CrossRef] [PubMed]

Kamieniecki, Gregory W. 2001. Prevalence of psychological distress and psychiatric disorders among homeless youth in Australia: A comparative review. Australian and New Zealand Journal of Psychiatry 35: 352-58. [CrossRef] [PubMed] 
Kessler, Ronald C., Gavin Andrews, Lisa J. Colpe, Eva Hiripi, Daniel K. Mroczek, S. -L. T. Normand, Ellen E. Walters, and Alan M. Zaslavsky. 2002. Short screening scales to monitor population prevalences and trends in non-specific psychological distress. Psychological Medicine 32: 959-76. [CrossRef] [PubMed]

Kessler, Ronald C., Peggy R. Barker, Lisa J. Colpe, Joan F. Epstein, Joseph C. Gfroerer, Eva V. Hiripi, Mary V. Howes, Sharon-Lise T. Normand, Ronald W. Manderscheid, Ellen E. Walters, and et al. 2003. Screening for serious mental illness in the general population. Archives of General Psychiatry 60: 184-89. [CrossRef] [PubMed]

Kessler, Ronald C., Jennifer Green, Michael J. Gruber, Nancy Sampson, Evelyn Bromet, Marius Cuitan, Toshi A. Furukawa, Oye Gureje, Hristo Hinov, Chi-Yi Hu, and et al. 2010. Screening for serious mental illness in the general population with the K6 screening scale: Results from the WHO World Mental Health (WMH) survey initiative. International Journal of Methods in Psychiatric Research 19: 4-22. [CrossRef] [PubMed]

Kidd, Sean, and Golan Shahar. 2008. Resilience in homeless youth: The key role of self-esteem. American Journal of Orthopsychiatry 78: 163-72. [CrossRef] [PubMed]

Kipke, Michelle D., Susanne B. Montgomery, Thomas R. Simon, and Ellen F. Iverson. 1997. "Substance Abuse" disorders among runaway and homeless youth. Substance Use and Misuse 32: 969-86. [CrossRef] [PubMed]

Marsden, P. V. 1987. Core discussion networks of Americans. American Sociological Review 53: 122-31. [CrossRef]

McCarthy, Bill, and John Hagan. 1992. Surviving on the street: The experiences of homeless youth. Journal of Adolescent Research 7: 412-30. [CrossRef]

Mewton, Louise, Ronald C. Kessler, Tim Slade, Megan Hobbs, Louise Brownhill, Louise Birrell, Zoe Tonks, Maree Teesson, Nicola Newton, Cath Chapman, and et al. 2016. The psychometric properties of the Kessler Psychological Distress Scale (K6) in a general population sample of adolescents. Psychological Assessment 28: 1232-42. [CrossRef] [PubMed]

Moskowitz, Amanda, Judith A. Stein, and Marguerita Lightfoot. 2013. The mediating roles of stress and maladaptive behaviors on self-harm and suicide attempts among runaway and homeless youth. Journal of Youth and Adolescence 42: 1015-27. [CrossRef] [PubMed]

National Coalition for the Homeless. 2017. Youth Homelessness [WWW Document]. Natl. Coalit. Homeless. Available online: http:/ / nationalhomeless.org/issues/youth/ (accessed on 26 June 2017).

National Health Care for the Homeless Council. 2015. Behavioral Health among Youth Experiencing Homelessness. A Quarterly Research Review of the National HCH Council. Washington: National Health Care for the Homeless Council.

Nyamathi, Adeline M., Ashley Christiani, Folasade Windokun, Tonia Jones, Aaron Strehlow, and Steve Shoptaw. 2005. Hepatitis $C$ virus infection, substance use, and mental illness among homeless youth: A review. AIDS 19: S34-S40. [CrossRef] [PubMed]

Perry, Brea L., and Bernice A. Pescosolido. 2015. Social network activation: The role of health discussion partners in recovery from mental illness. Social Science and Medicine 125: 116-28. [CrossRef] [PubMed]

Perry, Brea L., Erin Pullen, and Bernice A. Pescosolido. 2017. Interactions between patients' experiences in mental health treatment and lay social network attitudes toward doctors in recovery from mental illness. Network Science, 1-26. [CrossRef]

Pinkerton, John, and Pat Dolan. 2007. Family support, social capital, resilience and adolescent coping. Child $\mathcal{E}$ Family Social Work 12: 219-28. [CrossRef]

R Core Team. 2017. R: A Language and Environment for Statistical Computing. Vienna: R Foundation for Statistical Computing, Available online: https:/ / www.R-project.org/ (accessed on 5 February 2017).

Rew, Lynn, Margaret Taylor-Seehafer, Nancy Y. Thomas, and Ronald D. Yockey. 2001. Correlates of resilience in homeless adolescents. Journal of Nursing Scholarship 33: 33-40. [CrossRef] [PubMed]

Rice, Eric, Norweeta Milburn, Mary Jane Rotheram-Borus, Shelley Mallett, and Doreen Rosenthal. 2005. The effects of peer group network properties on drug use among homeless youth. American Behavioral Scientist 48: 1102-23. [CrossRef] [PubMed]

Rice, Eric, Norweeta G. Milburn, and Mary Jane Rotheram-Borus. 2007. Pro-social and problematic social network influences on HIV / AIDS risk behaviours among newly homeless youth in Los Angeles. AIDS Care 19: 697-704. [CrossRef] [PubMed]

Rice, Eric, Judith A. Stein, and Norweeta Milburn. 2008. Countervailing social network influences on problem behaviors among homeless youth. Journal of Adolescence 31: 625-39. [CrossRef] [PubMed]

Rizopoulos, Dimitris. 2006. 1tm: An R package for latent variable modelling and item response theory analyses. Journal of Statistical Software 17: 1-25. [CrossRef] 
Samejima, Fumiko. 1969. Estimation of latent ability using a response pattern of graded responses. Psychometrika Monograph Supplement 1: 17. [CrossRef]

Scott, John. 2017. Social Network Analysis. Thousand Oaks: SAGE.

Smith, Kristen P., and Nicholas A. Christakis. 2008. Social networks and health. Annual Review of Sociology 34: 405-29. [CrossRef]

Snyder, Susan M., Robin Hartinger-Saunders, Timothy Brezina, Elizabeth Beck, Eric R. Wright, Nicholas Forge, and Brian E. Bride. 2016. Homeless youth, strain, and justice system involvement: An application of general strain theory. Children and Youth Services Review 62: 90-96. [CrossRef]

Thoits, Peggu A. 2011. Mechanisms linking social ties and support to physical and mental health. Journal of Health and Social Behavior 52: 145-61. [CrossRef] [PubMed]

Toolis, Erin E., and Phillip L. Hammack. 2015. The lived experience of homeless youth: A narrative approach. Qualitative Psychology 2: 50-68. [CrossRef]

Toro, Paul A., Tegan M. Lesperance, and Jordan M. Braciszewski. 2011. The Heterogeneity of Homeless Youth in America: Examining Typologies. Washington: Homelessness Research Institute, Available online: http:/ / www.youthmovingforward.org/wp-content/uploads/2010/07/file_The_Heterogeneity_ of_Homeless_Youth_in_America1.pdf (accessed on 26 June 2017).

Tucker, Joan S., Jianhui Hu, Daniela Golinelli, David P. Kennedy, Harold D. Green, and Suzanne L. Wenzel. 2012. Social network and individual correlates of sexual risk behavior among homeless young men who have sex with men. Journal of Adolescent Health 51: 386-92. [CrossRef] [PubMed]

Tyler, Kimberly A. 2008. Social network characteristics and risky sexual and drug related behaviors among homeless young adults. Social Science Research 37: 673-85. [CrossRef] [PubMed]

Tyler, Kimberly A. 2013. Homeless youths' HIV risk behaviors with strangers: Investigating the importance of social networks. Archives of Sexual Behavior 42: 1583-91. [CrossRef] [PubMed]

Tyler, Kimberly A., and Lisa A. Melander. 2011. A qualitative study of the formation and composition of social networks among homeless youth. Journal of Research on Adolescence 21: 802-17. [CrossRef] [PubMed]

Tyler, Kimberly A., Sarah L. Akinyemi, and Lisa A. Kort-Butler. 2012. Correlates of service utilization among homeless youth. Children and Youth Services Review 34: 1344-50. [CrossRef] [PubMed]

U.S. Department of Health and Human Services, Family and Youth Services Bureau. 2013. Report to Congress on the Runaway and Homeless Youth Programs Fiscal Years 2010 and 2011; Washington: U.S. Department of Health and Human Services, Family and Youth Services Bureau.

Unger, Jennifer B., Michelle D. Kipke, Thomas R. Simon, Christine J. Johnson, Susanne B. Montgomery, and Ellen Iverson. 1998. Stress, coping, and social support among homeless youth. Journal of Adolescent Research 13: 134-57. [CrossRef]

Wellman, Barry. 2007. Challenges in collecting personal network data: The nature of personal network analysis. Field Methods 19: 111-15. [CrossRef]

Wenzel, Suzanne, Ian Holloway, Daniela Golinelli, Brett Ewing, Richard Bowman, and Joan Tucker. 2012. Social networks of homeless youth in emerging adulthood. Journal of Youth and Adolescence 41: 561-71. [CrossRef] [PubMed]

Wickham, Hadley. 2009. ggplot2: Elegant Graphics for Data Analysis. New York: Springer.

Wright, E. R., and R. E. Connoley. 2002. Empowering forces: Professional careworkers in the support networks of gay, lesbian, and bisexual youth. In Childcare E Inequality: Rethinking Carework for Children and Youth. Edited by Francesca M. Cancian, Demie Kurz, Andrew S. London, Rebecca Reviere and Mary C. Tuominen. Boston: Routledge-Kegan Paul, pp. 159-73.

Wright, Eric R., Erin Ruel, Morgan Justice Fuoco, Alex Trouteaud, Travis Sanchez, Ana LaBoy, Halley Myers, Kara Tsukerman, Christopher Vidmar, Matthew Gayman, and et al. 2016. Atlanta Youth Count! Homeless Youth Count and Needs Assessment Final Report. Available online: http: / atlantayouthcount.weebly.com/ uploads/7/9/0/5/79053356/aycna_final_report_may_2016_final.pdf (accessed on 18 June 2016).

(C) 2017 by the authors. Licensee MDPI, Basel, Switzerland. This article is an open access article distributed under the terms and conditions of the Creative Commons Attribution (CC BY) license (http:/ / creativecommons.org/licenses/by/4.0/). 